
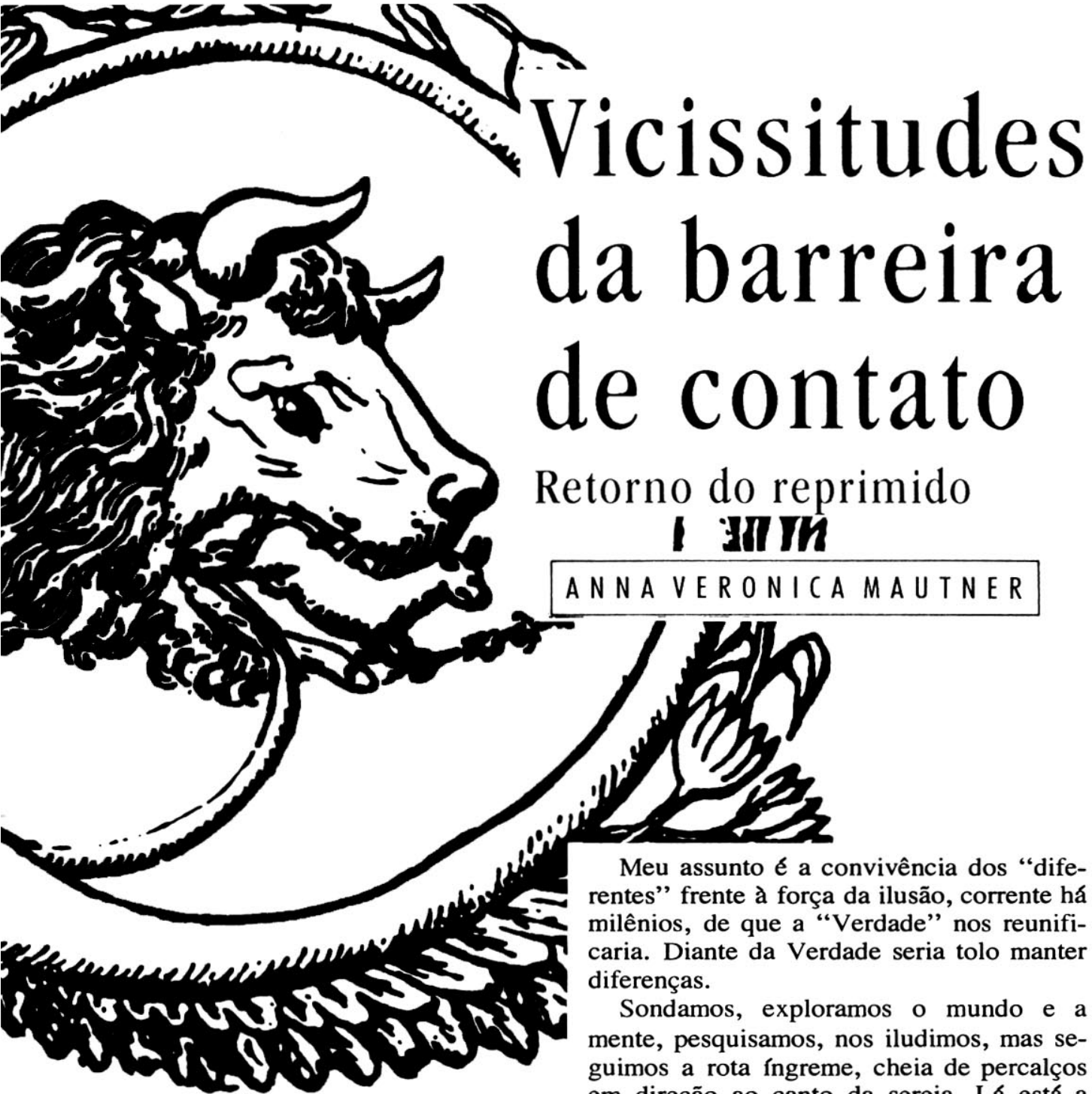

Retorno do reprimido I III Th

ANNA VERONICA MAUTNER

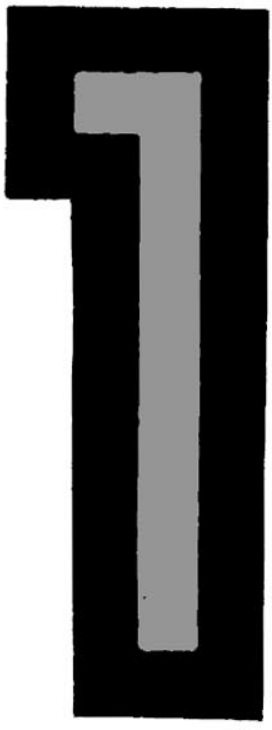

Meu assunto é a convivência dos "diferentes" frente à força da ilusão, corrente há milênios, de que a "Verdade" nos reunificaria. Diante da Verdade seria tolo manter diferenças.

Sondamos, exploramos o mundo e a mente, pesquisamos, nos iludimos, mas seguimos a rota íngreme, cheia de percalços em direção ao canto da sereia. Lá está a Verdade. Mas é sempre miragem.

Diante de milênios "Ocidentais Racionais" de busca inútil, fico por enquanto com a aparente inevitabilidade das diferenças, pois os não-céticos não têm que ser obrigatoriamente idealistas nem mesmo tolos. E eis que vou ao encontro da psicanálise que propõe seja procurado, não quem tem a verdade entre dois, nem aquele que está certo, mas propõe que vejamos o encontro dos dois. Para denominar este encontro escolhi a expressão "barreira de contato", pela ambigüidade que contém. Lançarei idéias, descreverei "os em torno" de uma trouvaille.

Falarei de psicanálise, mas também sobre o que se diz por ar, na aldeia global, do "revival" dos grupos nacionais ou nações marginalizadas do exercício do poder. Seria uma volta ao tribal? Digo "não" a isto para firmar a idéia de que o X da questão é como se encontram e não a qualidade dos que se encontram.

Na psicanálise, o que estou chamando de "barreira de contato" aparece sob o codinome de vínculo, transferência, contratransferência. Pensar ininterruptamente o contato constitui a psicanálise e a torna pro-
ANNA VERONICA MAUTNER É socióloga e psicanalista.

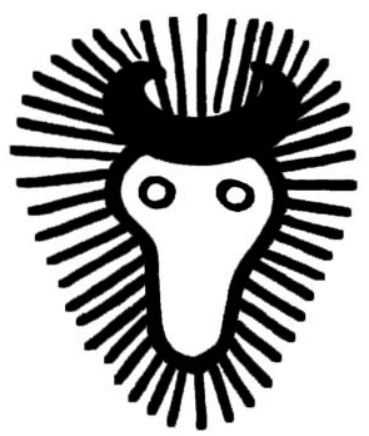

Acima, à esquerda, Jotma, 0

"poder" hindu-védico; $\theta$

" espirito do demónio e do

inferno", dos índios

norte-americanos 
1 Georges Devereux em seu artigo sobre identidades étnicas (1968) fala sobre os processos dissociativos e mesmo de entropia quando o outro é distante ou mesmo desconhecido.

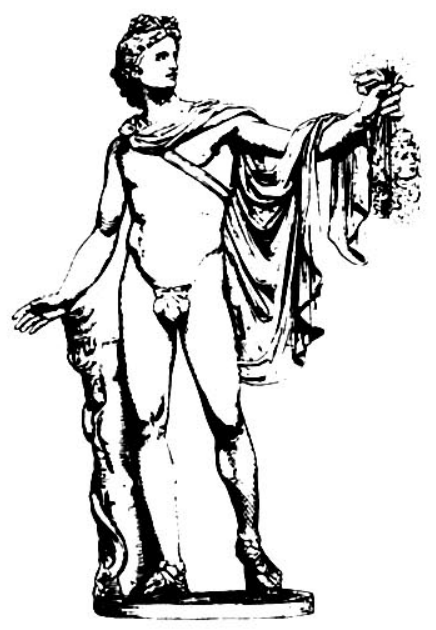

tótipo do contato de "diferentes" e ao mesmo tempo permite a compreensão das razões que a tornam tão revolucionária e tão polêmica.

Falando dela queria evitar os contratempos da discussão das questões sempre na ponta da língua dos que duvidam: qual psicanálise? O que e? De qual psicanálise quer falar esta gaja?

Evitemos pois as questões de praxe e façamos o esforço supremo de aceitar a existência de algo como psicanálise, alguma psicanálise. Procuremos não ser céticos.

Digamos que este nome criado pela mente humana, redundantemente empregado por tantos profissionais, escritores, curiosos, clientes, sofredores, se refira a um conjunto de idéias e/ou práticas. Digamos que existe.

Alimento a ilusão de despistar assim céticos, positivistas incluindo idealistas e tolos pois não posso ignorar um "nome" que se mantém na berlinda ou na trama de boa parte do que se pensa e escreve neste século. E mais, vem marcando fundo a maneira de pensar a ação e a própria ação. A sua persistência ao menos lhe garante uma existência. Em torno da barreira de contato - questão controversa - queria narrar uma história. Uma longa história, antiga e sem fim à vista, assim como funciona sem fim à vista a relação analítica.

Comecei esta história com todo meu engenho e arte há dois anos atrás. Então me detive em abordar a psicanálise em um canto do Império Austro-Húngaro e até escrevi sobre ela para esta mesma publicação, no número 6, dedicado à Europa Oriental.

Desde então, muro de Berlim derrubado veio a significar véus retirados. Quero dizer que estou às apalpadelas, sondando o que acontece na barreira de contato dos romanos e bárbaros, cristãos e pagãos, Oriente e Ocidente com seus corolários liberdade e totalitarismo - povos com escrita e sem escrita, nômades e sedentários, etc.

E a barreira de contato muda de lugar; é, ora rígida, ora flexível, ora porosa, ora impermeável. A história é escrita pelos que têm escrita. A história dos que não têm escrita é escrita na fronteira, no contato que se localiza numa barreira.

E onde entra ar a psicanálise, pergunta você?

Bem, eu quero situar esta idéia/prática/teoria/pensamento/ciência/arte ou a psicanálise como fronteira entre todo lá e todo cá. Pois é na forma que a psicanálise descreve o funcionamento da mente que encontra o paralelo desta coreografia de cinco milênios entre os cá e lá da história que conheço.

$\mathrm{Ou}$, quem sabe, serei mais feliz no meu intento se disser que a psicanálise descreve dentro de nós a dinâmica sem fìm da história sem fim (visível) dos confrontos entre grupos e povos? Em nenhum momento pretendo inserir aqui pensamento causal. Se escorregar, perdoem-me. Será sempre pura analogia ou contigüidade. Também não pretendo que seja o "cá" reflexo do "lá". Os dois existem e são captados pelo nosso aparelho perceptivo, coordenado com nossa memória elaborada pela mesma mente.

É a minha mente que me permite perceber a história do mundo e também a do homem singular. O senso comum não é obrigatoriamente o mundo dos tolos e dos crédulos. Nem a razão é a garantia de verdade. Por isso continuo pensando, sem contudo parar de duvidar.

Como mostrar que os fenômenos que percebo como barreiras de contato são iguais na sua dinâmica em todos os encontros de "diferentes"? Serão meus olhos ou minha mente que formam e deformam ou talvez será a própria barreira que se transmute? Bem, eu agora quero ir contando um pouco de história, ou um pouco de ilusão dos sentidos. Vou seguir a coreografia das malhas do contato. Os diferentes só o são porque se encontram sob minha percepção(1). E enquanto forem as diferenças que estiverem na mira de um projeto de equalização estaremos esterilmente rodando em falso. $O$ caminho está na compreensão do contato e de suas vicissitudes, só ấ está a possibilidade de interpretação.

A prática psicanalítica sendo a análise constante do vínculo pode ser um protótipo que esperamos. Convívio sem suicídio grupal ou individual. Conscientes no contato, viveremos, mesmo diferentes, mesmo em contato.

Mas eu vou contar um pouco de hist ória, antiguinha e ver com esperança renovada a possibilidade de poder ser so, de ser junto, sem ser em conjunto. Criar e recriar sem diluir. "Interminável é a análise" pois infinitas são as diferenças que entram em contato e infinitas realidades são reprimidas para manter diferentes as partes e por isso infinitos serão nossos contatos e a história.

Vamos pois brincar um pouco de mundo e sua história...

Houve tempo, houve lugares, alguns existem ainda, onde não era/ê tácito que todos os seres humanos fossem iguais, donde resulta que misericórdia, compaixão, respeito, não são tampouco universais. Este sentimento de humanidade, pois, nem sempre exis- 

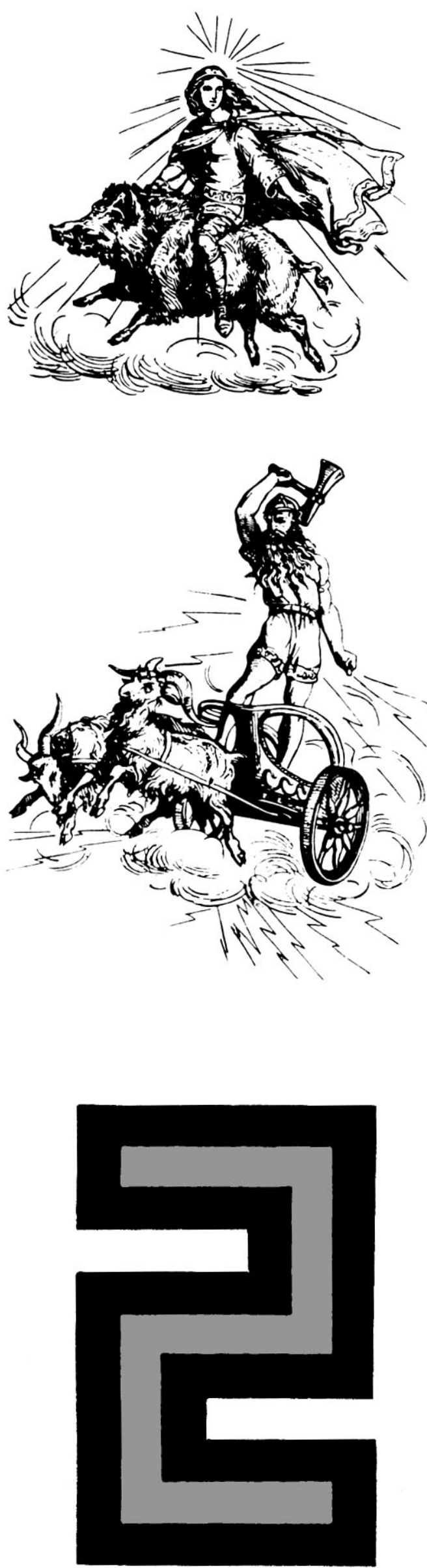

tiu. Todo s sabem, mas é preciso lembrar, que na antigüidade Ocidental, na Ásia Central, ou Extremo Oriente, o valor da vida humana, para nós sagrada, se bem que muitas vezes sejamos sacrflegos, podia ser um "nada". Nem a dor era uma coisa tão terrível. Destes fatos só nos restam os mitos depois escritos por aqueles que sacralizam o Homem. Quase tudo deste mundo iletrado parece perdido, restam so sinais. A mitologia germânica, dionisf́aca e cruel, o Olimpo, as tribos nômades cuja bravura ou visão diferentes da vida humana as tornavam mercenários perfeitos, foram trazidos das estepes da Ásia Central, como bandos de lutadores, para as fronteiras do Sacro Imperio, ora para defender-se dos romanos, ora para defendê-los. Bons guerreiros, lutavam com a força dos que aceitam a morte e por isso morrem e matam lutando.

Cinco mil anos convivemos com este outro mundo dalém das fronteiras da escrita, dalém da lei universal de defesa da vida e da propriedade. São mais de cinco mil anos e onde estavam neste tempo esta força ou estes povos e sua cultura?

No bebê e em suas fantasias inconscientes encontramos o homem dalem fronteiras. Diz a Melanie Klein que a culpa se instaurou em seguida ao nascimento. Será? Aqui, no mundo do domínio da razão e da escrita, temos culpa, superego, Édipo. Lá também, mas lá é menos importante. As proibições são poucas, só o incesto, e não são universais em sua forma. As regras, as leis do clã valem para o clã e não passa na cabeça deles que valham para todos os clãs. Cada tribo, cada clã tem suas normas rígidas. Suas. Os outros são outros com os quais não nos identificamos e nem pretendemos torná-los nossa imagem e semelhança.

A tradição oral não pode ser espalhada pelos quatro cantos da Terra. Só no face a face é que podemos controlar sua exatidão e correição na transmissão.

O surgimento da escrita, especialmente por ser portátil, atacou de frente o univeso tribal. Uma cultura se espalhou célere, e papiros, pedras, paredes das cavernas tornaram-se testemunhas do certo e do errado. As histórias então orais e sonoras viraram mitos e verbetes, e assim penetraram sorrateiramente no universo da ideologia igualitária, propiciada pela razão, racionalismo, monoteŕsmo, humanismo, carregadas nos papiros portáteis.

Da barbárie à civilização - um caminho que nunca foi feito. A barbárie está aqui em cada um de nós e as guerras européias do século XX não deixam lugar para engano. E ấ estão os croatas vindos no século III do vale do Dnieper lutando ainda pelo seu direito de não ser universal, tal estão os
Na outra página, estátua do deus grego Apolo; acima, Fro-Freyr, deus nórdico do " sol e do crescimento" ; $\theta$ Thor-Thunar, deus nórdico da "tempestade e da guerra" 
curdos, os magiares, moldavos, etc. Não importam os tratados assinados em Yalta, Versailles ou Verdun. Os clãs, as pequenas nações resistem. Suas barreiras de contato foram atacadas, mas não entendidas.

No limiar deste século parece que os bárbaros de nosso mundo ressurgiram do que pensávamos fossem só cinzas. Não eram não, lá estão, como uma força brutal de vida que reaparece quando nós esgotamos idealismo, romantismo, iluminismo, isto é, as possibilidades de conter, universalizar emoções. A arte tamberm foi ao seu limite e ar chegou a vez das ciências humanas tentarem explicar por que razão em 2.500 anos não venceram estes "grupelhos" $?^{(2)}$ Nações sofridas, fustigadas pelo racionalismo, atacadas pela(s) fê(s) com intuitos universais (judaicos, cristãos, maometanos). E ainda assim querem seus d aletos, seus nomes, suas letras estranhas, sua mitologia e liberdade de viver, sofrer, ter prazer e também morrer. Estes "grupelhos" cantam. Estouram nossos ouvidos, os ciganos. Os tchecos não querem sentar na mesma mesa que os eslovacos. Os magiares odeiam "baixos alemães" mas se dão bein com os ciganos que não se misturam com ninguém. E todos rejeitam os judeus que na surdina influem há cinco mil anos com sua alfabetização compulsória e universal nos ritos de culpa de todo mundo. Não mates, não roubes, respeita teus pais, a mulher do próximo. E onde fica o meu desejo e o meu querer?

Fiquem quietos... nós agüentamos não satisfazer nossos desejos, somos especiais. Especiais são os judeus, especiais são os maometanos, os gregos, os troianos, e os turcos e os armênios e os georgianos e os outros também são especiais.

Mas aí entra de novo a procura da Verdade: queremos que todos sejam iguais a nós. Submetam-se à minha verdade, pois eu sou igual a você ou você é igual a mim. Aŕ vem a Razão, o direito Romano, o Cristianismo. Abre-se a temporada do proselitismo. Todos querem espalhar aos quatro cantos sua verdade, escrita no papiro pelo calígrafo. E aí vale matar, roubar, saquear, trucidar. Siga-me ou morre. Alguns especiais não foram nessa. Nenhum grupo africano se interessou pelo que existia além do seu horizonte. Os judeus em geral não querem converter, os ciganos também acreditam e mantêm suas leis para si próprios. E assim os lapões, os croatas, os tchecos, os armênios, os curdos. Uns nômades, outros sedentários, mas todos antiguinhos no apego a si mesmo ${ }^{(3)}$.

São 5.500 anos de contato e não se deglutiram, não se fundiram. E por que agora todos põem a cabecinha para fora deixando-nos perplexos? Os sêrvios não se sentam à mesma mesa que os croatas. Os eslovacos odeiam os magiares. $\mathrm{O}$ que é isto no século $\mathrm{XX}$ ?

Freud - judeu nascido numa destas regiões subjugadas (Bóznia-Herzegovina) que os habsburgos pensavam devagar diluir - vai a Viena e diz que ao nascer somos todos polimorfos perversos e que a civilização é repressão e sublimação.

Este tema ocupou filosofos que o esmiuçaram com talento. Mas as ciências humanas, diferente do pensamento filosófico, datam do século XIX e são elas que tratam "cientificamente" do assunto tornando-o normativo.

Quem pode, quem sabe, nos fazer aceitar a "barbárie", eliminar 5.500 anos de culpa? Algum partido, alguma nação, algum filósofo? Ou o marxismo, quem sabe? Não.

Pode caber à psicanálise, a estes judeus, Freud e Melanie Klein, seguidos de outros, que não suportaram mais a culpa de serem dos bárbaros também, e, não mais acreditando nas soluções metafísicas transcendentes, nem no mito do socialismo do homem racional, abriram novo espaço de pensamento: o pensar o vínculo da psicanálise.

Mas o que podia fazer a psicanálise com estas brasas há tanto tempo enterradas sob milênios de cinzas? Disse que estão lá - na raiva, no odio, na inveja. Nascemos fracos, com medo, e logo ficamos sabendo que vamos morrer um dia, e que da luta da vontade de viver e do destino de morrer nasceriam o homem e suas fantasias.

As walkírias dançam, são pura vida; as amazonas guerreiam, os deuses do Olimpo não conhecem limites a seus desejos. Dor, amor, inveja, morte, vingança - palavras de Melanie Klein para descrever o bebê.

E o que se quer deste bebê psicanalítico? Que agüente as agruras da vida deixando prevalecer o bom na luta com o mal-estar gerado pela condição de nossa própria espécie.

Vivemos um momento muito especial na história. De tanto falarmos e pensarmos o humano, esquecemos que somos tamberm indivíduos que procuram ser primo inter paris. Mas veja-se: paris. Paris ê clã, ê grupo conhecido. Seria preciso que nos apercebêssemos de nossas semelhanças depois de esforços concentrados de mais de cinco milênios de razão para que fôssemos mais socializados e cada vez menos indivíduos-bebês.

Não deu certo. As duas partes convivem no mundo e em cada cidadão singular.

Escrevemos, imprimimos, pintamos, fotografamos, filmamos, televisamos. Tudo para 

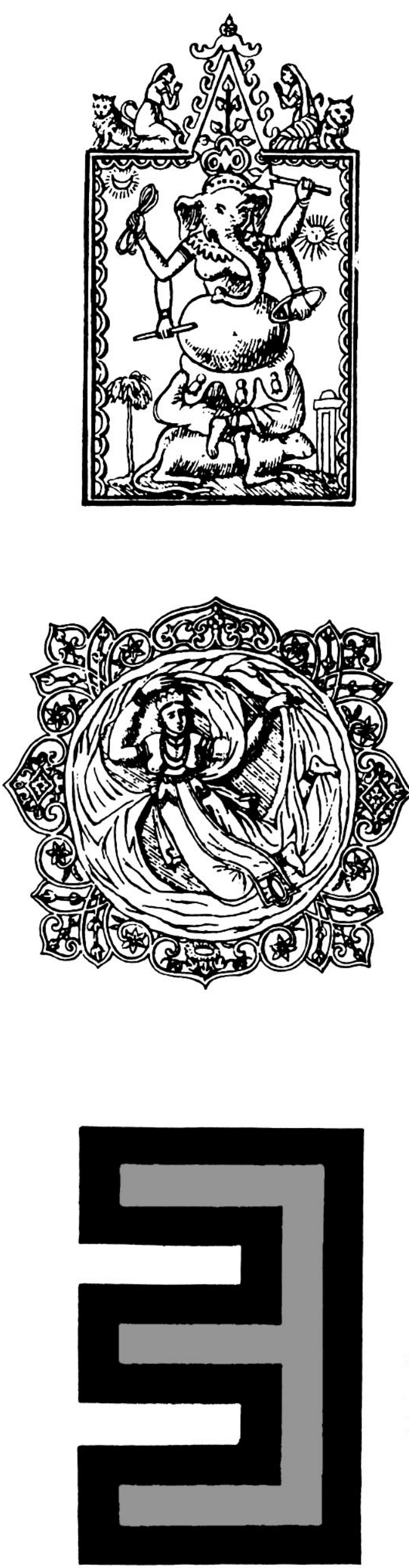

apagar um pouco as diferenças. Constituŕmos finalmente a aldeia global de homens iguais que são todos diferentes entre si e nem por isso deixam de procurar seus pares. Que pares serão estes se somos iguais? $\mathrm{Na}$ falta de melhor, vamos voltar às tribos bárbaras boas de canto, dança e luta e cruéis como crianças?

Não. Vamos focalizar a barreira de contato que por cinco milênios nos enganou pela sua flexibilidade, porosidade, etc., a tal ponto que muitas vezes se pensou que a barreira nem existisse mais.

Lego engano.

A psicanálise (não a teoria psicanalítica) é um momento, uma nesga do tempo no qual ocorre uma ligação, um fato entre duas pessoas. Comunicação oral, visual, gestual, de cheiros e fantasias. Um contato único, único em cada tempo e exclusivo do par participante.

Essencialmente incomunicável, pleno de idéias, metáforas, sons, ritmos, esta ligação à qual chamam vínculo ocorre no real, mas está predominantemente no imaginário. Todo contato é assim, todo fato social é assim, mas o que é próprio e exclusivo deste é que ele mesmo é o objeto a ser focalizado. Se quiser retê-lo na memória, lança-se mão de certos truques da mente, se quiser tentar comunicá-lo, lança-se mão de outras habilidades de linguagem verbal e não-verbal e pode-se ainda triturá-lo na descrição exaustiva com vistas a compreender o que pode ser compreendido, permitindo que o que resta reflua para donde veio, ao universo da própria intimidade não partilhada nem pelo outro no outro extremo do vínculo.

Psicanálise, pois, é a aproximação máxima ao vínculo que ocorre entre duas pessoas, mas que jamais será alcançado nem por terceiros, nem pelos partícipes. Viveu, acabou.

Mas existe uma teoria psicanalítica que vem sendo elaborada a partir do que se consegue depreender desta vivência.

A situação psicanalítica é o espaço do reprimido, pré-escrito, inescrevível, redundante, conservador como é a cultura oral, espaço da compulsão à repetição. A teoria que é escrita permite recorrer ao vivido e transformá-lo, repensá-lo. A teoria, que pertence ao universo letrado, é onde podemos evoluir, transformar, inclusive o próprio vínculo. Este por ser o universo sonoro oral seria conservador, permanentemente repetido.

Em um extremo do vínculo está o profissional apto e bem-formado, que, conhecedor da teoria e vivenciando a unicidade de cada momento, pode inserir a mudança no vínculo porque sua posição no par é a da-

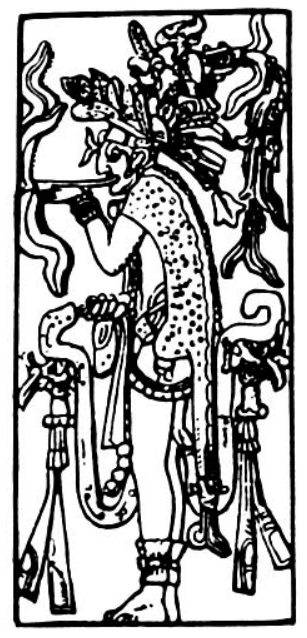

De cima para baixo e da esquerda para a direita: Ganesha, deus védico da "sabedoria"; Maja, a "mãe de todas as coisas" hindu; sacerdote do altar da cruz, cultura maia de Palenque, México 


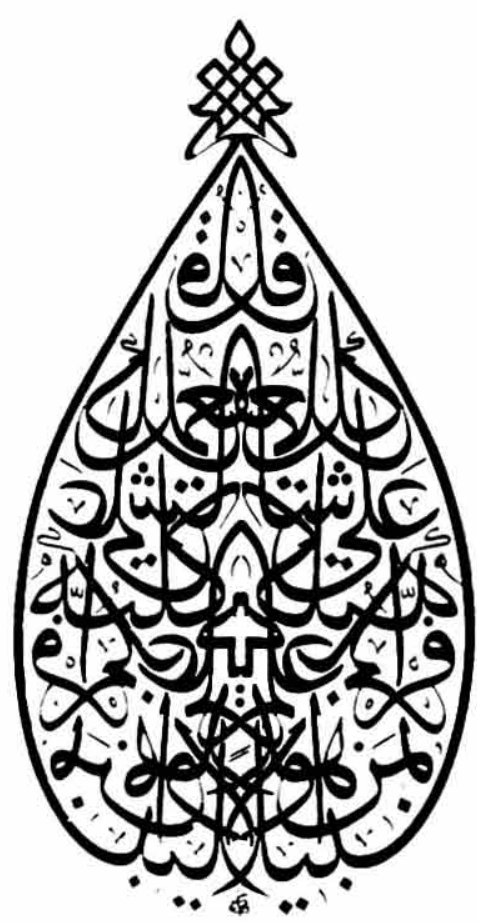

Oração árabe; abaixo, o símbolo da serpente dos incas peruanos

4 Georges Devereux, Identidade Étnica, 1967.

quele que contém o pensamento. Reinserido o pensamento, o vínculo dos mesmos dois se transforma. É a ação diferente dos diferentes.

$\mathrm{O}$ analista, na situação analítica, torna-se barreira de contato entre dois universos através da linguagem. Assim como o letrado foi transformando o universo bárbaro/pagão/iletrado ao escrever os mitos, sem contudo deglutir ou conseguir se apropriar da dinâmica da história do outro, assim a interpretação muda o vínculo sem transformar dois em um. Continua existindo analista e analisando num sem fim, porque algo de cada um permanecerá para sempre inacessível.

Barreira de contato

Fronteira de contato

Territorio de fronteira

Terra de ninguém

- Interpretação

Este é o locus do romano, do cristão, do psicanalista, da psicanálise e também da interpretação.

É sobre o fato posto em evidência pelos ventos do "revival" dos tártaros, tchecos, moldavos, magiares, curdos, etc. que eu penso. Será um reviver? O fato de não ter sido sempre focalizado não indicaria ausência. $O$ jogo de figura e fundo é parte da dinâmica da percepção. Hoje é dia da razão, amanhã será do originário. Hoje e amanhã. A história da humanidade e de cada homem contém a coreografia dos diferentes. Inútil é o esforço para igualar, banalizar. É na integração dos diferentes que nos revelamos. O momento analítico onde os diferentes encaram a diferença faz interminável a análise pois infinitas são as diferenças entre homens, povos, épocas, culturas.

Lembrei-me agora de um fato in-crível, mas compreensível.

Em Praga há uma parte da cidade que nunca pertenceu à nobreza, nem ao clero oficial, nem se refere a batalhas ou fatos heróicos, mas que está estranhamente bem conservada: o gueto. Inúmeras sinagogas (sete), o cemitério, três museus, as ruas... Por quê?, perguntei eu a Paola Lidmilova, tradutora do português para o tcheco, que me ciceroneava. Ela respondeu: “Aqui, Hitler resolveu que seria o Museu da Raça Extinta. Orientou seus generais que enviassem para Praga as peças representativas das comunidades e lares judeus destruídos e esvaziados".

A memória é essencial mesmo quando a ação é cruel, impensável. A ação sem registro gera mera redundância. É preciso marcar a presença do ato. No caso, do encontro, da barreira de contato.

Hitler, os arianos e seus seguidores intuíram que a especificidade que tanto enalteciam sర existiria enquanto os "diferentes" (judeus, comunistas, ciganos) existissem. Um universo só ariano entraria em dissociação, diluição ou, melhor dizendo, em entropia ${ }^{(4)}$.

E por isto quiseram criar o museu que seria a memória eterna do "outro" e teria não a função de preservar a memória da coletividade judaica, mas a de manter a identidade étnica dos arianos.

\section{BIBLIOGRAFIA E FONTES INSPIRADORAS}

- Vários verbetes da Enciclopédia Britânica

- Germania de Tácito

- Os Celtas de Júlio César

- Um pouco de Descartes

- Oswaldo Porchat e seus pirrônicos, céticos

- Georges Devereux

- Ethnopsychinalyse Complementariste, cap. VI - Flamarion

- Vinland Saga - Classic Penguin

Mais:

- Uma cabeça cheia de Freud, Melanie Klein e Ferenczi

- Uma origem centro-européia
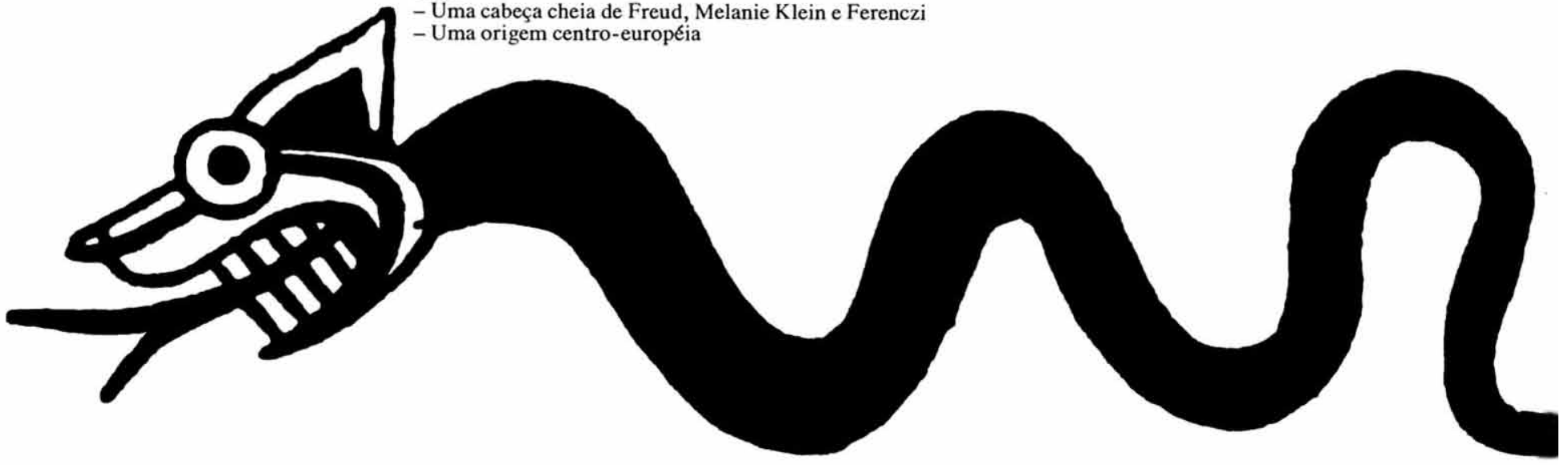